\title{
Maximum Power Point Tracking for a Point Absorber Device with a Tubular Linear Switched Reluctance Generator
}

\author{
Rui Mendes , Maria do Rosário Calado ${ }^{(D)}$ and Sílvio Mariano* \\ University of Beira Interior and Instituto de Telecomunicações, Calçada Fonte do Lameiro, \\ 6201-001 Covilhã, Portugal; rui.mendes@lx.it.pt (R.M.); rc@ubi.pt (M.d.R.C.) \\ * Correspondence: sm@ubi.pt; Tel.: +351-275-329-935
}

Received: 16 July 2018; Accepted: 16 August 2018; Published: 22 August 2018

\begin{abstract}
This paper addresses the control of a Tubular Linear Switched Reluctance Generator (TLSRG) with application in a point absorber device. A maximum power point tracking (MPPT) strategy is proposed to maximize the power extraction from ocean waves. The generator is characterized by average maximum force of $120 \mathrm{kN}$ and a maximum velocity of $1.3 \mathrm{~m} / \mathrm{s}$. The proposed MPPT is achieved by changing the generator damping load according to the excitation force induced by a regular wave. A hysteresis controller is applied to regulate the phase current intensity which allows the control of the linear force provided by the generator. The conversion system direct current (DC) bus voltage is adjusted by an isolated DC/DC converter with a proportional integral controller to define the appropriate duty-cycle.
\end{abstract}

Keywords: tubular linear generator; switched reluctance machine; ocean wave energy; direct drive conversion

\section{Introduction}

The point absorber devices with direct drive extraction mechanism are the more efficient systems for ocean wave energy conversion at low velocity oscillations [1]. For this type of conversion devices, linear generators with permanent magnets are generally used [2-6]. However, linear electric machines with permanent magnets need a complicated winding system and are characterized by their elevated construction and assembly costs. This type of machine is affected by the gradual demagnetization of the permanent magnets, which may reduce the machine efficiency and compromise its operation [7]. With the absence of permanent magnets in its configuration, the switched reluctance machine is a strong alternative as linear generator for direct conversion devices. It is suitable for low speed operation, presents a robust and low cost construction and is characterized by a high reliability [8]. In point absorbers, motion is induced by the ocean waves to drive a power-take-off (PTO) system for the generation of useful energy [9]. Maximum power absorption can be attained when the frequency of the floating body matches the frequency of the incoming ocean waves, where the excitation force is in phase with the velocity of the oscillating body. However, since the ocean waves are characterized by a variable behavior, an active control needs to be applied to improve the conversion efficiency of the device among the different sea states [10].

The control of an ocean wave converter aims to adjust the PTO load in order to achieve the optimal oscillation phase and amplitude, required for maximum power absorption [11]. The point absorber converter can operate under continuous control or discrete control. In continuous control, an optimum load force is provided by the PTO system to regulate the amplitude and/or the phase of the floating body motion. With latching control, which belongs to the category of discrete control, the motion of the floating body is held until the incoming wave force achieves the most suitable phase value [12]. 
The complex-conjugate control and passive loading are the continuous control techniques with more acceptance for point absorber devices [11]. The former seeks a resonant motion of the floating body by changing respective amplitude and phase while the latter only modifies the amplitude by adjusting the converter dynamic resistance to improve the power absorption from the incoming waves. In [13], a control strategy based on fuzzy logic is proposed to control the amplitude and phase of a point absorber device to enhance the respective power capture. A passive loading strategy is presented in [14] to control a point absorber device with a linear permanent magnet synchronous generator as PTO. The control is applied in the electronic power converter by emulating the electric resistance of the generator in order to maximize the wave power extraction. With the same objective, in [15], the current of the generator is regulated by changing the converter DC link voltage for an optimal value. With this strategy, the electrical load in the generator can be modified and, as consequence, the most favorable damping may be provided by the ocean wave converter. In [16] are proposed reactive and latching control strategies for a direct-drive point absorber to maximize the electric power output instead of power extracted by the device. These strategies aims to reduce the copper losses in a permanent magnet linear generator and to increase the energy extraction near the device excursion limits. Model predictive control is another technique that has been adopted for ocean wave converters. In this type of control, the system behavior is predicted over a short time horizon in order to estimate the optimal damping force to be applied for maximum energy extraction [17]. A nonlinear model predictive control has been implemented and tested by Son and Yeung [18] on a lab-scale permanent-magnet linear generator. A damping control control strategy has been proposed in [19] for high-speed operation of ocean wave energy converter with a linear permanent magnet synchronous generator. In [20], a novel robust model predictive control is presented for application in heaving wave energy converters to maximize the power conversion output while accounting with the device motion constraints. In the latter approach, the PTO force is parameterized using orthogonal polynomials in order to reduce the computational complexity verified in standard model predictive control techniques.

The maximum power point tracking control technique (MPPT), widely used in renewable energy converters, has shown promising results when applied to the control of a point absorber device with a permanent magnet linear generator, as experimentally demonstrated by Lettenmaier et al. [21]. The proposed strategy regulates the electric load according to the change verified in the ocean wave converter output power. In [22] is proposed an MPPT technique that applies an active phase control in a point absorber device with a linear permanent magnet generator. The generator damping is modified according to the wave period to reduce the phase difference between the system velocity and excitation force in order to reach the maximum power point absorption.

In the present paper, a MPPT strategy to control a tubular linear switched reluctance generator (TLSRG) that serves as PTO in a point absorber device is proposed.

The work was developed to promote the application of tubular linear switched reluctance generators direct-drive ocean wave energy converters. Since this type of machine offers unique advantages, it is of extreme importance to develop practical and efficient techniques for its control and operation to make it a a reliable and attractive solution. Unlike the majority of the optimal control techniques for this type of ocean wave converters, the proposed approach does not use the dynamical model of the device to predict optimal behavior. Moreover, the proposed control strategy does not require additional hardware for its operation. Thus, the complexity of controller is heavily reduced which makes it easier to implement.

\section{System Description}

The configuration of the point absorber conversion system with the proposed approach is illustrated in Figure 1. The representative blocks of each subsystem are described in detail.

The point absorber device illustrated in Figure 2 is considered in the present work to evaluate the performance of the TLSRG as PTO. The conversion system is characterized by a floating buoy of cylindrical shape and a floating submerged reference system where the TLSRG is held. The reference 
system is assumed to be fixed to bottom by means of mooring cables. Thus, only heave motion is allowed for the floating buoy and for the movable part of the TLSRG, which are assumed to be rigidly connected. A mechanical spring is considered to connect the oscillating body to the reference system in order to assist the body motion, if necessary.

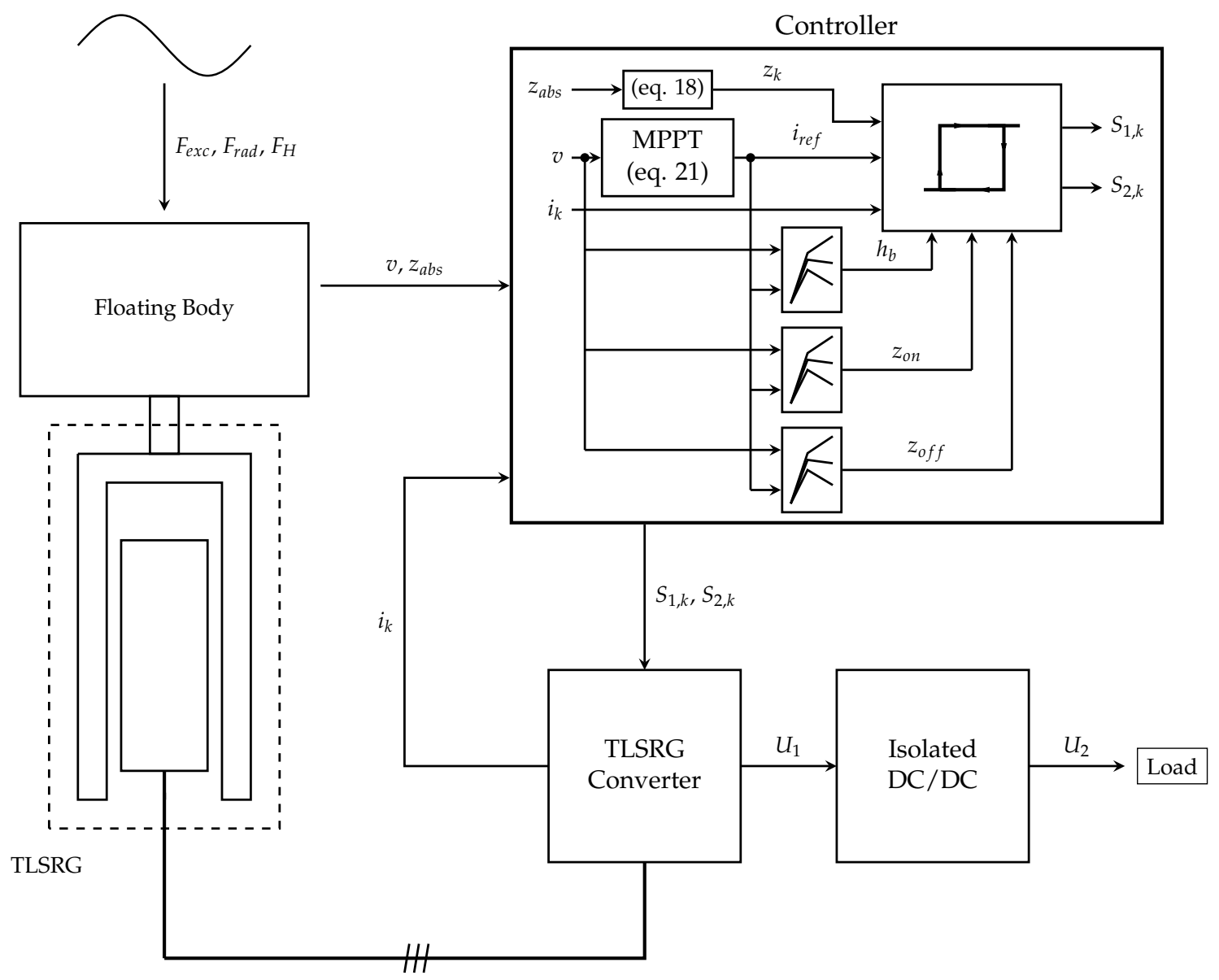

Figure 1. Configuration of the point absorber conversion system with the proposed approach.

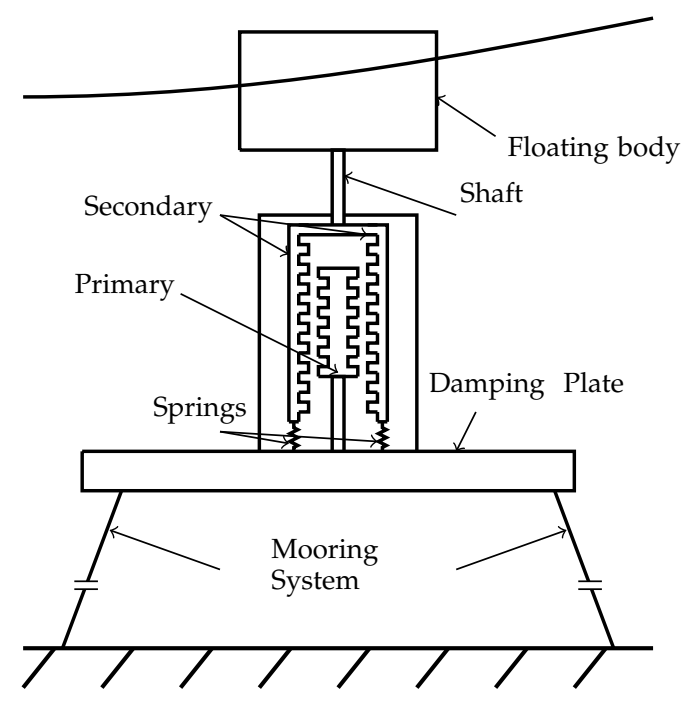

Figure 2. Point absorber schematics. 
The TLSRG, used as PTO system, is illustrated in Figure 3. The electromagnetic structure is derived from the flat switched reluctance machine evaluated in [7] and was already proposed and analyzed as tubular generator in [23].

The TLSRG has three electric phases with one coil of $N_{t}$ turns per phase. Each electric phase possesses a distinct magnetic circuit, separated from the adjacent phases by a non-magnetic element.

The mathematical model of the switched reluctance machine is obtained through the electrical analysis of the power electronic converter used for the linear switched reluctance generator. In the present work, the H-bridge asymmetric converter is adopted to control the process of electromechanical energy conversion in the generator. The converter topology for one phase is shown in Figure 4. Since all electric phases have the same electric circuit configuration, the mathematical model is generalized for just one.
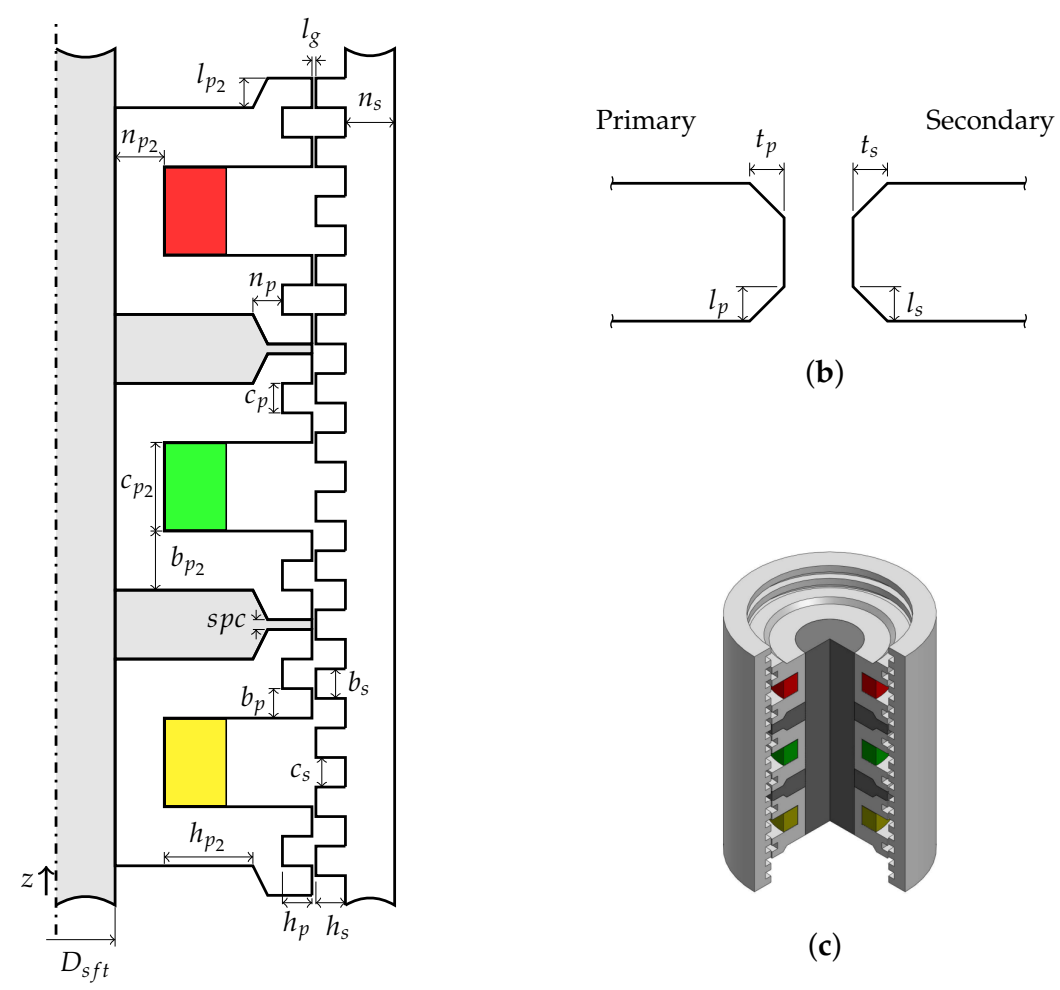

(b)

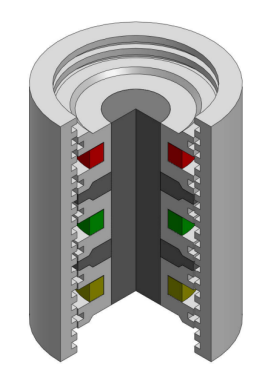

(c)

(a)

Figure 3. Tubular linear switched reluctance generator (TLSRG) used as PTO: (a) longitudinal cross-sectional profile; (b) tooth shape; and (c) 3D illustration.

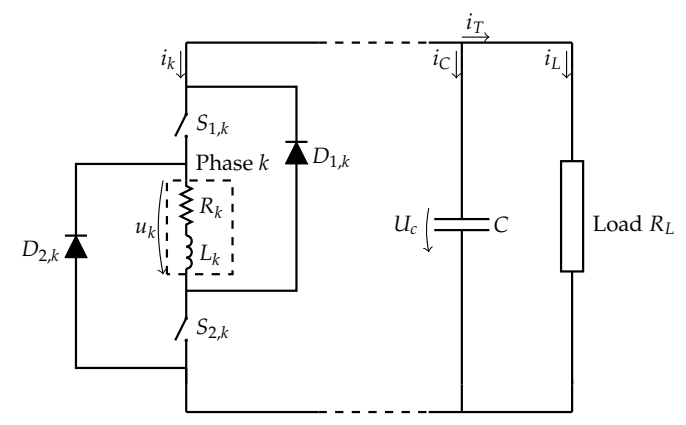

Figure 4. Electric circuit for one phase.

A DC/DC converter is used to control the electric energy flux between the TLSRG converter and the load, as schematized in Figure 1. Thus, the voltage levels at the DC bus and at the load terminals can 
be properly adjusted to improve the system performance. For the present work, an isolated H-bridge $\mathrm{DC} / \mathrm{DC}$ converter is adopted. Since the purpose of the DC/DC is to regulate the energy delivered to the load by means of pulse width modulation, its parameters are not designed and, therefore, an ideal converter is assumed. The latter is illustrated in Figure 5.

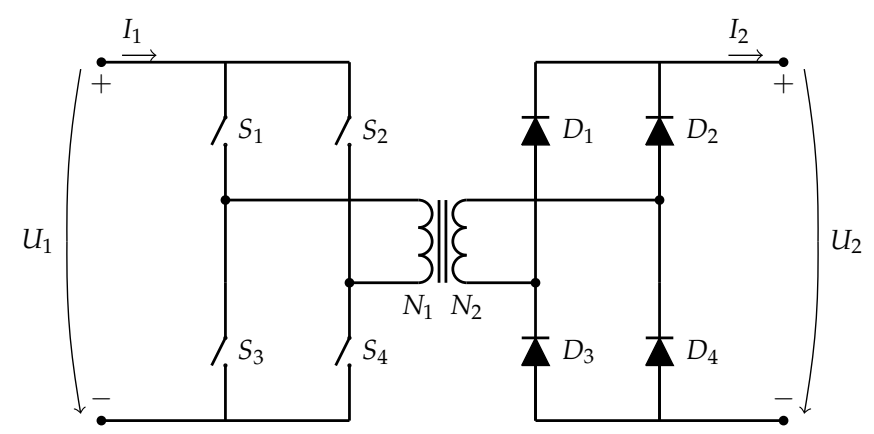

Figure 5. Ideal circuit for the isolated H bridge DC/DC converter (adapted from [24]).

\section{Mathematical Model}

\subsection{Point Absorber}

To study the dynamic performance of each generator, it is necessary to formulate the mathematical model of the respective conversion system. For evaluation purposes, in addition to the forces resulting from the interaction between the oscillating body and the ocean waves, only the TLSRG damping force $F_{g e n}$ and the spring force $F_{S}$ are considered. During the process of energy absorption, the WEC system is actuated by the wave excitation force $F_{e x c}$, the radiation force $F_{r a d}$, the hydrostatic force $F_{H}$ and the viscous damping force $F_{V}$. As given in [25], the equation of motion for the point absorber system is:

$$
m_{c} \ddot{z}=F_{\text {exc }}(t)+F_{\text {rad }}(t)+F_{H}(t)+F_{V}(t)+F_{S}(t)+F_{\text {gen }}(t)
$$

with $m_{c}$ the total mass of the oscillating body (floating body and movable part of the TLSRG) and $\ddot{z}$ the respective acceleration.

The excitation force $F_{e x c}$ can be calculated as:

$$
F_{\text {exc }}(t)=\Re\left[\sum_{k=1}^{N}\left(\sqrt{2 S\left(\omega_{k}\right) \Delta \omega}\right) \tilde{F}_{\text {exc }}\left(\omega_{k}\right) e^{i\left(\omega_{k} t+\phi_{k}\right)}\right]
$$

where, for $N$ regular waves, $S\left(\omega_{k}\right)$ is the spectral density for the angular frequency $\omega_{k}, \Delta \omega$ is the angular frequency step, $\phi_{k}$ is the wave phase defined, randomly, within $[0,2 \pi]$ and $\tilde{F}_{e x c}\left(\omega_{k}\right)$ is the complex value of the excitation force per metre of wave amplitude.

For the radiation force, one has:

$$
F_{\text {rad }}(t)=-m_{\infty} \ddot{z}-\int_{0}^{t} K_{r}(t-\tau) \dot{z}(\tau) \mathrm{d} \tau
$$

with $m_{\infty}$ the added mass for infinite frequencies, $K_{r}$ the radiation velocity impulse response and $\dot{z}$ the oscillating body velocity.

The hydrostatic force can be calculated as:

$$
F_{H}(t)=-\rho_{w} g A_{w} z
$$

where $\rho_{w}$ is the specific mass of sea water, $g$ is the gravity acceleration, $A_{w}$ is the cross-sectional area of the submerged part of the floating body and $z$ is the vertical position of the oscillating body. 
The viscous drag suffered by the floating body is accounted by the following quadratic damping force:

$$
F_{V}(t)=-\frac{1}{2} \rho_{w} C_{D} A_{D}|\dot{z}-\dot{\eta}|(\dot{z}-\dot{\eta})
$$

In Equation (5), the parameter $A_{D}$ represents the cross-sectional area of the floating body, $C_{D}$ the viscous drag coefficient and $\dot{\eta}$ the vertical velocity of the water. The viscous damping force is applied on the cylindrical floating body. It is assumed that the revolution axis of the floating body is parallel to the water flow as a result of the respective vertical motion. The shape of the floating body is accounted in the damping force with the value of the drag coefficient $C_{D}$, given in [26] as function of the buoy radius $a$ and vertical extension $h_{f}$.

The spring force is given by the spring stiffness $k_{s}$ and the oscillating body position $z$ as:

$$
F_{S}(t)=-k_{s} z
$$

\subsection{TLSRG}

The mathematical model of the switched reluctance machine is obtained through the electrical analysis of the power electronic converter illustrated in Figure 4. Neglecting the mutual inductance effects between phases, the voltage of the electric phase $u_{k}$ is given by:

$$
u_{k}=R_{k} i_{k}+\left(L_{k}\left(z_{k}, i_{k}\right)+i_{k} \frac{d L_{k}\left(z_{k}, i_{k}\right)}{d i_{k}}\right) \frac{d i_{k}}{d t}+v i_{k} \frac{d L_{k}\left(z_{k}, i_{k}\right)}{d z_{k}}
$$

where, for each phase $k, R_{k}$ is the internal electric resistance, $i_{k} i$ the electric current, $L_{k}\left(z_{k}, i_{k}\right)$ is the linkage magnetic flux, $z_{k}$ is the phase electric position and $v=\frac{d z_{k}}{d t}$ is the linear velocity of the secondary.

According to the notation indicated in Figure 4, the capacitor voltage $U_{c}$ is related with its electric current $i_{c}$ and the respective capacitance $C$ as:

$$
i_{c}=C \frac{d U_{c}}{d t}
$$

The value of the total electric current that flows from the generator to the capacitor and to the resistive load $R_{L}$ can be calculated from:

$$
i_{T}=\sum_{k=1}^{3} i_{k}
$$

The capacitor electric current is associated with the total electric current from the generator and with the electric current in the load $i_{L}$ :

$$
i_{c}=i_{T}-i_{L}
$$

The converter bus voltage $U_{b u s}$ is defined by the voltage of the capacitor:

$$
U_{b u s}=U_{c}
$$

Depending on the electronic switches states, the voltage at each phase terminals $u_{k}$ is:

$$
u_{k}=\left\{\begin{array}{cl}
U_{b u s}-2 U_{s}, & S_{1, k} \text { and } S_{2, k} \text { Closed } \\
-U_{b u s}-2 U_{D}, & S_{1, k} \text { and } S_{2, k} \text { Open } \\
-U_{D}-U_{s}, & S_{1, k} \text { Open and } S_{2, k} \text { Closed }
\end{array}\right.
$$

where $U_{s}$ and $U_{D}$ are, respectively, the voltage drops of each electronic switch and free-wheeling diode. 
For the linear force developed by the generator $F_{g e n}$, one has:

$$
F_{\text {gen }}(t)=\sum_{k=1}^{q} F_{e m, k}\left(z_{k}, i_{k}\right)
$$

where $F_{e m, k}$ is the electromechanical force contribution of phase $k$.

During each process of energy transfer between the elements of the TLSRG, the mean electric power $\bar{P}_{e}$ is defined as:

$$
\bar{P}_{e}=\frac{1}{\Delta t} \int_{t_{0}}^{t_{1}} u i \mathrm{~d} t=\frac{W_{e}}{\Delta t}
$$

where $W_{e}$ represents the transferred electric energy during the time interval $\Delta t=t_{1}-t_{0}$.

The mean value of the mechanical power $\bar{P}_{\text {mec }}$ that is possible to extract from the secondary, at a given constant velocity $v$, can be estimated from the mean value of the electromechanical force $\bar{F}_{g e n}$ developed by the generator:

$$
\bar{P}_{m e c}=\bar{F}_{g e n} v
$$

for $\Delta t=t_{1}-t_{0}$.

With the mean values of the generated electric power $\bar{P}_{\text {gen }}$ and input mechanical power $\bar{P}_{\text {mec }}$, the electromechanical conversion efficiency $\eta_{e}$ can be calculated as:

$$
\eta_{e}=\frac{\bar{P}_{g e n}}{\bar{P}_{m e c}}
$$

with $\bar{P}_{m e c}$ given by Equation (15) and $\bar{P}_{\text {gen }}$ computed as follows:

$$
\bar{P}_{g e n}=\frac{W_{g e n}}{\Delta t}
$$

The mathematical model has been formulated as function of the phase electric position. The latter represents a value between the two opposing non-alignment positions of the phase. As the secondary moves, the electric position describes a periodic profile. The relation between the electric position of one phase $z_{k}$ and the mechanical position of the secondary $z_{\text {mech }}$ is defined by:

$$
z_{k}=-S_{t}+\left(\frac{z_{m e c h}-k_{o f f s e t}-S_{t}}{2 S_{t}}-\left\lfloor\frac{z_{m e c h}-k_{\text {offset }}-S_{t}}{2 S_{t}}\right\rfloor\right) 2 S_{t}
$$

where $S_{t}$ is the displacement described by the movable part between the alignment and the non-alignment positions and $k_{o f f s e t}$ represents the distance between the same electric position of two consecutive phases. Equation (18) is represented in Figure 6.

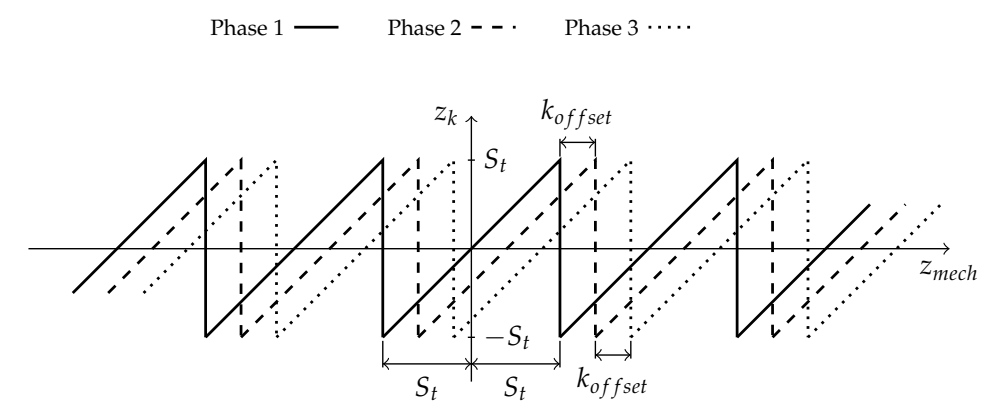

Figure 6. Electric position as function of mechanical position.

The ideal mathematical model of the isolated DC/DC converter illustrated in Figure 5 allows establishing the relation between the mean values of input voltage and input current in the converter 
$\left(\bar{U}_{1}\right.$ and $\left.\bar{I}_{1}\right)$ with the same electrical output entities $\left(\bar{U}_{2}\right.$ and $\left.\bar{I}_{2}\right)$. As given in [24], for these physical entities, we have:

$$
\begin{gathered}
\bar{U}_{2}=2 \bar{U}_{1} \mathcal{D} \frac{N_{2}}{N_{1}} \\
\bar{I}_{1}=2 \bar{I}_{2} \mathcal{D} \frac{N_{2}}{N_{1}}
\end{gathered}
$$

where $N_{1}$ is the number of coils of the transformer primary, $N_{2}$ is the number of coils of the transformer secondary and $\mathcal{D}$ is the duty-cycle of the control signal.

\section{Proposed Control}

The operation of a switched reluctance machine is conditioned by the electric positions where the electronic switches are commutated. With fixed positions, especially at variable velocities, the system may become unstable leading to significant changes in voltage, according to the electric load of the converter. Thus, to avoid this undesirable behavior, there is the need to apply a closed loop control to the machine.

In the operation as a generator, the control must be applied to preserve the converter DC bus electric voltage and achieve maximum conversion efficiency [27]. The voltage of the DC bus can be maintained within a pretended value by using a DC/DC converter to regulate the energy supplied to the load [28]. The conversion efficiency relies on the overall system behavior which, for the present application, is conditioned by the damping of the electromechanical force exerted by the TLSRG. Therefore, the maximum performance can be achieved by adapting the strength and duration of the referred force, controlling the electric phase current intensity and the electronic switch commutation positions.

Point absorber devices are characterized by long period oscillations. Consequently, a low frequency operation is expected for the TLSRG under evaluation. For this operating condition, the electromotive force developed at the generator phase terminals may not be sufficient to overcome the DC bus voltage and, thus, the phase current may be forced to diminish progressively, leading to a premature extinction. To avoid this drawback, the current intensity must be maintained near a reference value by regulating the voltage applied to the electric phase with an hysteresis or pulse with modulation controller $[29,30]$.

The control of the TLSRG comprises the selection of the appropriate values for the parameters responsible for its performance. At high velocities, where the induced electromotive force is superior to the DC bus voltage, only the electric positions are accounted. At low velocities, a reference value for the electric phase current must also be considered.

The optimal control parameters can be computed off-line and related with the physical entities that reflects the machine performance. The optimal values can be determined with experimental measurements or computed with the generator mathematical model and included in the control process through look-up tables or mathematical expressions. With this approach, the appropriate values for the control parameters can be defined as function of the generator operation variables [31]. Other techniques applied in switched reluctance generator use a PI controller to perform on-line estimation of the optimal control parameters. In [7], the PI controller is adopted to regulate the electric phase current intensity of linear switched reluctance generator in order to minimize the converter output ripple.

However, despite the simplicity and robustness of the PI controller, its performance is strongly affected when the system is characterized by a non-linear behavior or when the control parameters are modified. For this case, control techniques based on artificial intelligence are a better approach due to the ability to handle the non-linearities of the system to be controlled [32]. 
The amount of energy available in ocean waves is not constant, although it may be characterized by a well defined periodicity during long periods. Thus, since the wave power changes over time, an adaptive control must be applied to ensure that the converter always extracts the maximum available energy. This can be achieved with maximum power point tracking (MPPT), a technique that has been already applied as the control of linear permanent magnet generator to attain maximum power absorption in a direct drive points absorber [33]. Concerning the switched reluctance machine, the MPPT was adopted by Xiong et al. [34] to control a rotating generator in a wind conversion device.

\subsection{Hysteresis Control}

The hysteresis control is applied to confine the phase current intensity close to a reference value. The need for this type of control arises from the low speed operation expected for the TLSRG which, usually, leads to the development of an electromotive force lower than the DC bus voltage.

In the hysteresis control, the error $e_{i}$, given by the difference between the phase current $i$ and the respective reference value $i_{r e f}$, is maintained within a range of values defined by the hysteresis band $h_{b}$. When the error is higher than $\frac{h_{b}}{2}$, the electronic switches are closed to apply the converter bus voltage $U_{b u s}$ to the phase terminals to increase its current value. When $e_{i}$ is lower than $-\frac{h_{b}}{2}$, the electronic switches are opened and the phase is subjected to a negative voltage $-U_{b u s}$ forcing the respective current to decrease [35]. Thus, with the hysteresis control, the generator conversion cycle is defined by successive excitation and generation periods. Figure 7a shows the typical current profile obtained by the hysteresis control. Figure $7 \mathrm{~b}$ shows the respective control logic diagram. In each electric phase, the generation cycle is initiated at the electric position $z_{o n}$, when the electric switches are closed to energize the coils, and it finishes at the position $z_{o f f}$, where the electric current starts to decrease until is extinguished at the position $z_{\text {ext }}$.

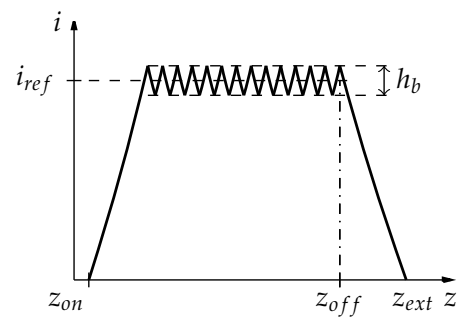

(a)

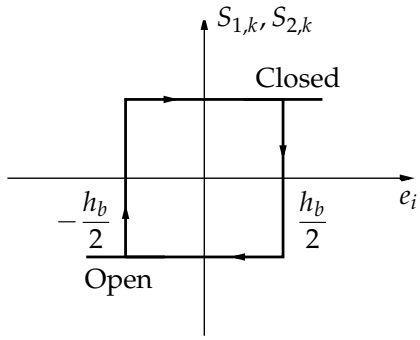

(b)

Figure 7. Hysteresis control: (a) phase electric current profile; and (b) control logic.

\subsection{MPPT}

The adopted MPPT technique for the present system is similar to the algorithm proposed by Xiong et al. [34] for a rotative switched reluctance generator, where the current in the electric phases is adjusted to provide the optimal torque for maximum electric power output. However, in the present work, instead of the electric power output, the velocity of the oscillating body is accounted as a measure of the system power conversion. Since the former is subjected to an higher rate of change, as a consequence of the successive excitation/generation cycles, it is difficult to follow its value in order to provide an appropriated control.

Knowing the velocity of the movable part of the TLSRG, its linear force can be controlled to follow the load induced by the ocean waves. This process is accomplished by regulating the electric current in each phase of the TLSRG. When the absolute value of the velocity increases, the acceleration of the oscillating system is positive, which implies positive net force on the oscillating body. In this situation, the electric phase current intensity can be raised to increase the damping provided by the TLSRG and, as a consequence, the conversion of kinetic energy in to electricity as well. As the wave excitation force 
starts to diminish, the generator becomes over-damped and the velocity starts to decrease, reducing the amount of kinetic energy available for conversion. Therefore, the electric phase current must be continuously reduced while a loss of velocity is verified. To apply the described control procedure, the reference value $i_{\text {ref }}$ for the electric current is computed by:

$$
\begin{aligned}
& i_{r e f}(t)=\left\{\begin{array}{cl}
i_{r e f}(t-1)-\Delta i & v(t)<v(t-1) \\
i_{r e f}(t-1)+\Delta i & v(t)>v(t-1) \\
0 & v(t)=v(t-1) \text { or } v(t-1)=0
\end{array}\right. \\
& \text { for: } \\
& 0<i_{\text {ref }}(t) \leq i_{\text {ref,max }}
\end{aligned}
$$

where $\Delta i$ is the incremental value defined for $i_{r e f}$ and $i_{r e f, \max }$ is the maximum value allowed for the latter.

Equation (21) allows establishing the reference value for the electric phase current at the instant $t$. This value, given between 0 and $i_{\text {ref,max }}$, is subjected to an update period $T_{a c t}$. For a correct control operation, the values for the hysteresis band $h_{b}$, the switch on position $z_{o n}$ and the switch off position $z_{\text {off }}$ shall be properly selected. In the present work, the referred parameters are selected as function of the velocity $v$ and reference current $i_{\text {ref }}$ from a set of optimal values. These values are previously computed to achieve maximum power generation for given combination of velocity and reference current. Look-up tables are used to store the values and they are assessed by the controller using linear interpolation.

\subsection{Proportional Integral (PI) Control}

The voltage of the converter DC bus is regulated by a proportional and integral (PI) controller, which provides the value of the duty-cycle $\mathcal{D}$ to be applied to the isolated DC/DC converter according to the error verified between the DC bus voltage and its reference value. The mathematical expression for the PI controller is given in [36] by:

$$
s(t)=K_{p} e(t)+K_{i} \int_{0}^{t} e(\tau) \mathrm{d} \tau
$$

where $s$ is the control variable, $e$ is the error associated with the entity to be controlled and $K_{p}$ and $K_{i}$ are the proportional and integral gains, respectively.

The value of the duty-cycle supplied to the isolated DC/DC is defined by an initial value $\mathcal{D}_{\text {init }}$ and by the result returned from the PI controller $\Delta \mathcal{D}$ :

$$
\mathcal{D}(t)=\mathcal{D}_{\text {init }}+\Delta \mathcal{D}(t)
$$

The parameter $\Delta \mathcal{D}$ is obtained through:

$$
\Delta \mathcal{D}(t)=K_{p} e_{U}(t)+K_{i} \int_{0}^{t} e_{U}(\tau) \mathrm{d} \tau
$$

where $e_{U}$ is the normalized error between the voltage in the DC bus and the respective reference value $U_{r e f}$ :

$$
e_{U}(t)=\frac{U_{r e f}-U_{b u s}(t)}{U_{r e f}}
$$

\section{Results and Analysis}

To evaluate the performance of the TLSRG as a PTO, a regular wave was considered to represent a sea state with a significant height of $4.4 \mathrm{~m}$ and a energetic period of $7.7 \mathrm{~s}$. The floating body was 
defined with a radius of $1.5 \mathrm{~m}$ and a vertical extension $h_{f}$ of $5.6 \mathrm{~m}$. The TLSRG has been designed with the capability to provide a mean damping force of, approximately, $120 \mathrm{kN}$, which is the maximum value expected for the ocean wave excitation force. Since the only concern is the control of the TLSRG, the respective electromagnetic design is omitted in the present work. The M19 silicon-steel is used as magnetic material, assuming that the ferromagnetic core is made of longitudinal laminations, radially oriented. The dimensions of the TLSRG, according to the nomenclature of Figure 3, are presented in Table 1. The electromagnetic characteristics were computed with MagNet ${ }^{\circledR}$, a commercial software that uses the Finite Element Method (FEM) for electromagnetic analysis. The results, obtained from a 2D magneto-static analysis, are displayed in Figure 8. The magnetic flux density distribution for the alignment and non-alignment positions can be found in Figure 9.

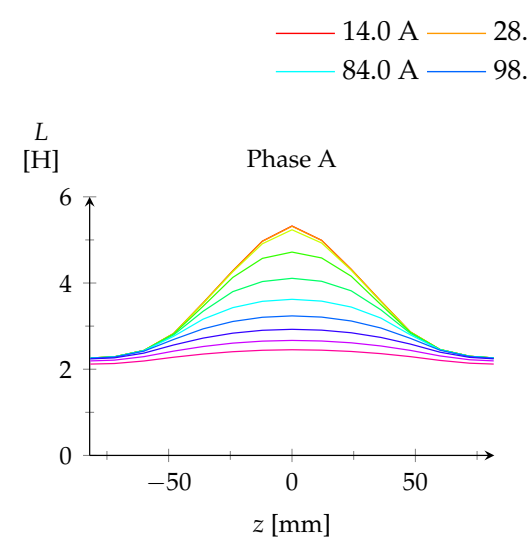

(a)
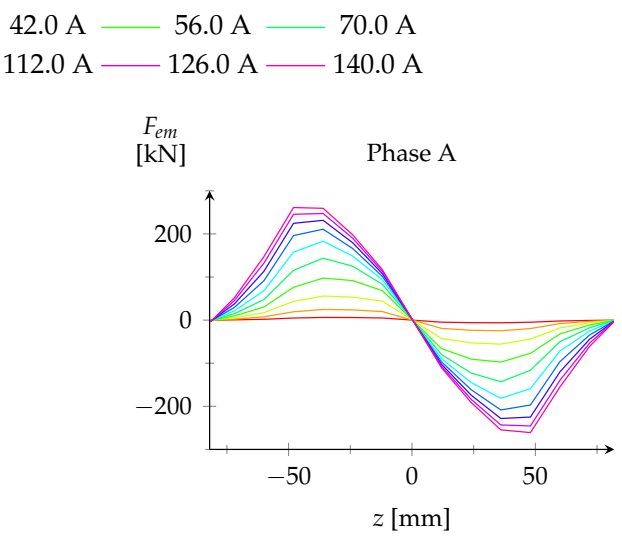

(b)

Figure 8. Electromagnetic characteristics for the electric phase A of the TLSRG: (a) inductance; and (b) axial force.

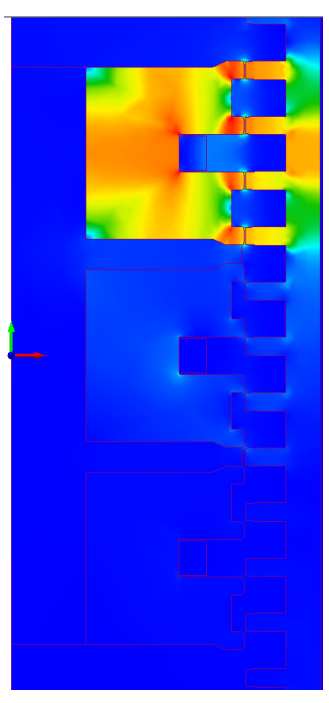

(a)

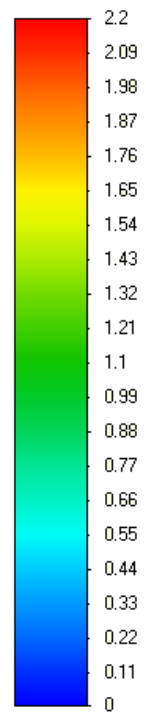

(1)

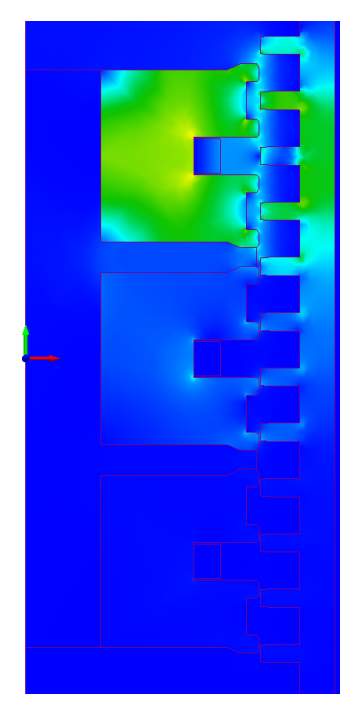

(b)

Figure 9. Distribution of magnetic flux density (in Tesla) for electric phase A with a current intensity of 100 A at: (a) alignment position; and (b) non-alignment position.

The hydrodynamic loads and the added mass were calculated in Nemoh, an open source software developed by Babarit and Delhommeau [37] based on the Boundary Element Method (BEM). The obtained profiles for the excitation force and impulse response function can be observed in 
Figure 10. The added mass results, as well as the dynamic properties of the oscillating body for the given regular wave, are presented in Table 2.

Table 1. Dimensional parameters of the TLSRG.

\begin{tabular}{|c|c|c|c|c|c|c|c|c|c|}
\hline $\begin{array}{c}l_{g} \\
{[\mathrm{~mm}]}\end{array}$ & $N_{t}$ & $\begin{array}{c}D_{s f t} \\
{[\mathrm{~mm}]}\end{array}$ & $\begin{array}{c}w_{h} \\
{[\mathrm{~mm}]}\end{array}$ & $\begin{array}{c}w_{v} \\
{[\mathrm{~mm}]}\end{array}$ & $\begin{array}{c}b_{p} \\
{[\mathrm{~mm}]}\end{array}$ & $\begin{array}{c}c_{p} \\
{[\mathrm{~mm}]}\end{array}$ & $\begin{array}{c}n_{p} \\
{[\mathrm{~mm}]}\end{array}$ & $\begin{array}{c}h_{p} \\
{[\mathrm{~mm}]}\end{array}$ & $\begin{array}{c}l_{p} \\
{[\mathrm{~mm}]}\end{array}$ \\
\hline 5.3 & 271.6 & 443.7 & 0.1 & 4.4 & 53.5 & 110.0 & 55.9 & 36.3 & 6.9 \\
\hline $\begin{array}{c}t_{p} \\
{[\mathrm{~mm}]}\end{array}$ & $\begin{array}{c}b_{p_{2}} \\
{[\mathrm{~mm}]}\end{array}$ & $\begin{array}{c}c_{p_{2}} \\
{[\mathrm{~mm}]}\end{array}$ & $\begin{array}{c}n_{p_{2}} \\
{[\mathrm{~mm}]}\end{array}$ & $\begin{array}{c}h_{p_{2}} \\
{[\mathrm{~mm}]}\end{array}$ & $\begin{array}{c}l_{p_{2}} \\
{[\mathrm{~mm}]}\end{array}$ & $\begin{array}{c}t_{p_{2}} \\
{[\mathrm{~mm}]}\end{array}$ & $\begin{array}{c}s p c \\
{[\mathrm{~mm}]}\end{array}$ & $\begin{array}{c}b_{s} \\
{[\mathrm{~mm}]}\end{array}$ & $\begin{array}{c}c_{s} \\
{[\mathrm{~mm}]}\end{array}$ \\
\hline 6.1 & 199.9 & 110.0 & 276.7 & 100.0 & 17.1 & 38.3 & 55.5 & 54.7 & 108.8 \\
\hline $\begin{array}{c}n_{s} \\
{[\mathrm{~mm}]}\end{array}$ & $\begin{array}{c}h_{s} \\
{[\mathrm{~mm}]}\end{array}$ & $\begin{array}{c}l_{s} \\
{[\mathrm{~mm}]}\end{array}$ & $\begin{array}{c}t_{s} \\
{[\mathrm{~mm}]}\end{array}$ & $\begin{array}{c}d_{\text {wire }} \\
{[\mathrm{mm}]}\end{array}$ & $\begin{array}{c}S_{t} \\
{[\mathrm{~mm}]}\end{array}$ & $\begin{array}{c}k_{\text {offset }} \\
{[\mathrm{mm}]}\end{array}$ & & & \\
\hline 102.9 & 117.5 & 2.7 & 29.3 & 5.3 & 81.8 & 54.5 & & & \\
\hline
\end{tabular}

Table 2. Floating body characteristics and hydrodynamic loads.

\begin{tabular}{ccccccccc}
\hline $\begin{array}{c}\boldsymbol{Z} \\
{[\mathrm{m}]}\end{array}$ & $\begin{array}{c}\omega \\
{[\mathrm{rad} / \mathbf{s}]}\end{array}$ & $\begin{array}{c}\boldsymbol{m}_{f} \\
{[\mathbf{k g}]}\end{array}$ & $\begin{array}{c}\boldsymbol{m}_{\text {gen }} \\
{[\mathbf{k g}]}\end{array}$ & $\begin{array}{c}\boldsymbol{d}_{f} \\
{[\mathbf{m}]}\end{array}$ & $\begin{array}{c}\boldsymbol{m}_{\boldsymbol{a}} \\
{[\mathbf{k g}]}\end{array}$ & $\begin{array}{c}\boldsymbol{m}_{\infty} \\
{[\mathbf{k g}]}\end{array}$ & $\begin{array}{c}\omega_{n} \\
{[\mathrm{rad} / \mathbf{s}]}\end{array}$ & $\begin{array}{c}\boldsymbol{F}_{\text {exc }} \\
{[\mathbf{k N}]}\end{array}$ \\
\hline 2.2 & 0.61 & $1.8 \times 10^{3}$ & $34,976.7$ & 5.1 & 7379.0 & 6895.7 & 1.3 & 124.1 \\
\hline
\end{tabular}

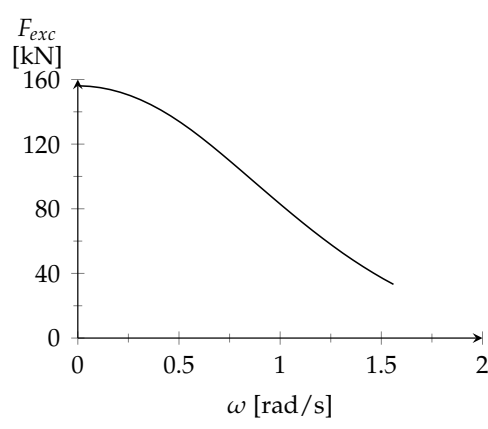

(a)

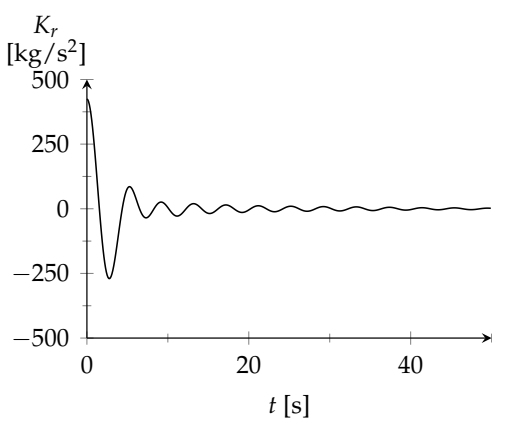

(b)

Figure 10. Wave-body iteration loads: (a) excitation force; and (b) radiation velocity impulse response.

The dynamic behavior of the TLSRG was evaluated for different velocities and reference current values, in order to identify the optimal control parameters. To accomplish this task, the Box Complex optimization method was applied following the same procedure described in [38]. For each combination of velocity and current values, an optimization process was applied to the mathematical model of the TLSRG where the switching electric positions and the hysteresis band width were considered as optimization variables. In this process, the isolated DC/DC converter was omitted from the mathematical model and the generated electric power was directly delivered to a resistive load. For each evaluation, two simulations were always performed. The first was used to compute the electric load needed to consume the average electric generated power and the second to give the pretended data. A capacitance of $0.05 \mathrm{~F}$ was assumed for the capacitor in the converter and the initial bus voltage was defined as $6 \mathrm{kV}$. Each simulation time was set to $1 \mathrm{~s}$.

For optimization purposes, $z_{d w e l l}$, the electric distance between $z_{o n}$ and $z_{o f f}$, was assumed as control variable and $z_{\text {off }}$ was established as $z_{o f f}=z_{o n}+z_{\text {dwell }}$. The control parameters $h_{b}, z_{o n}$ e $z_{\text {dwell }}$ were optimized to achieve maximum electric power generation. The optimal results are displayed in Figure 11. To obtain valid solutions for the electric positions, the following conditions were imposed:

$$
z_{\text {on }}>-S_{t} \quad z_{\text {on }}+z_{\text {dwell }}<S_{t} \quad z_{\text {dwell }} \geq 0
$$


The numerical limits for $z_{o n}$ and $z_{d w e l l}$ were established as function of $S_{t}$ by the relations defined below:

$$
-\frac{1}{2} S_{t} \leq z_{\text {on }} \leq \frac{1}{2} S_{t} \quad \frac{1}{5} S_{t} \leq z_{\text {dwell }} \leq \frac{3}{2} S_{t}
$$

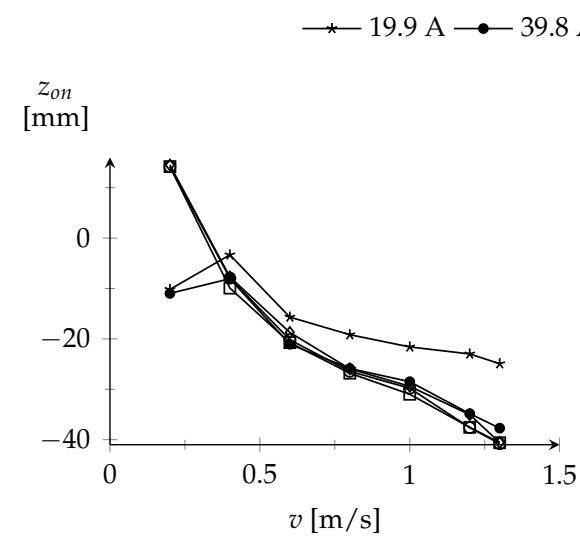

(a)

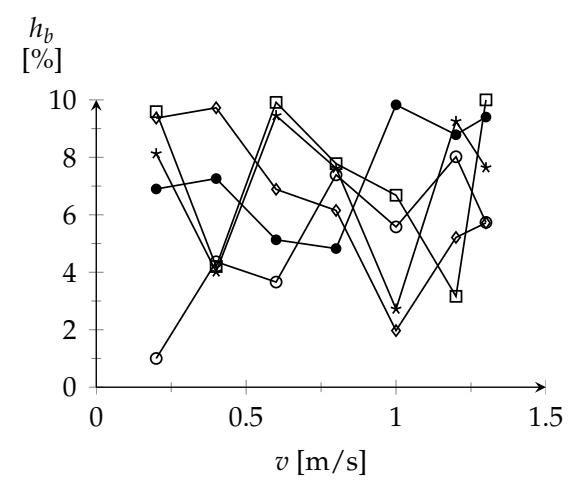

(c)

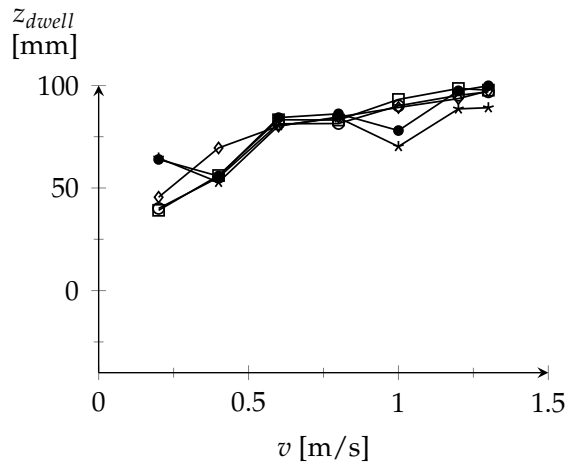

(b)

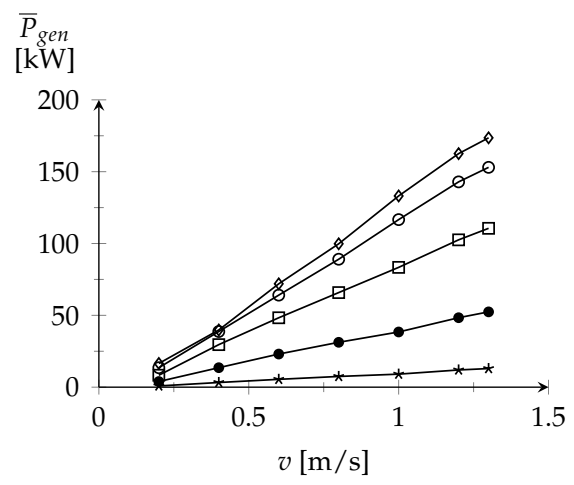

(d)

Figure 11. Optimal values obtained for: (a) $z_{o n} ;$ (b) $z_{d w e l l} ;$ (c) $h_{b}$; and (d) $\bar{P}_{g e n}$.

Knowing the optimal values for the hysteresis band and the electrical switching positions, the study of the TLSRG was redirected to the analysis of the TLSRG performance as PTO in a point absorber. The mathematical model described by Equation (1) was implemented in Simulink ${ }^{\circledR}$. A value of $1025 \mathrm{~kg} / \mathrm{m}^{3}$ was assumed for the specific mass of sea water $\rho_{w}$ and the drag coefficient $C_{D}$ was established as 0.86 . Since the natural frequency of the oscillating body is higher than the angular frequency of the excitation regular wave, the system cannot naturally achieve a resonant operation. Thus, the spring stiffness $k_{s}$ was considered zero to not increase the difference between these oscillating frequencies. In the point absorber model, the optimal control parameters computed off-line are introduced with look-up tables and computed by linear interpolation. The ratio $\frac{N_{2}}{N_{1}}$ was defined as 15 to provide a voltage of $400 \mathrm{~V}$ to the load when the DC bus is at $6 \mathrm{kV}$ and the switching duty cycle $\mathcal{D}$ of the isolated DC/DC converter is 0.5. For the PI controller applied to the isolated DC/DC converter, the proportional gain $K_{p}$ and integral gain $K_{I}$ were tuned with the values 4954 and 494 , respectively. The dynamic model was set to be simulated during the period of the considered regular wave.

The performance of the conversion system was evaluated assuming a constant value for $i_{r e f}$ and applying the proposed MPPT strategy. For the first case, the behavior of the system has been 
evaluated for 10 different values of $i_{r e f}$. The mean value of the generated electrical power $\bar{P}_{g e n}$ and the electric conversion efficiency $\eta_{e}$, for each value of $i_{r e f}$, are displayed in Figure 12 . For the second case, the system was subjected to an optimization process to search the optimal values of $T_{\text {act }}$ and $\Delta i$ for maximum electric power generation. The optimal value search was conducted by the Box Complex method, within the boundaries defined by $5 \times 10^{-3} \mathrm{~s}$ and $1 \mathrm{~s}$ for $T_{a c t}$, and defined by $1 \times 10^{-1} \mathrm{~A}$ and $7 \mathrm{~A}$ for $\Delta i$. As a result, the optimal values of $6.8 \times 10^{-2} \mathrm{~s}$ and $6.8 \mathrm{~A}$ were computed for $T_{a c t}$ and $\Delta i$, respectively.

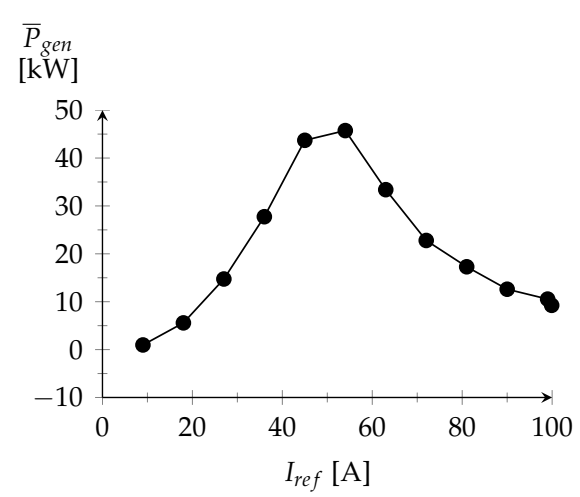

(a)

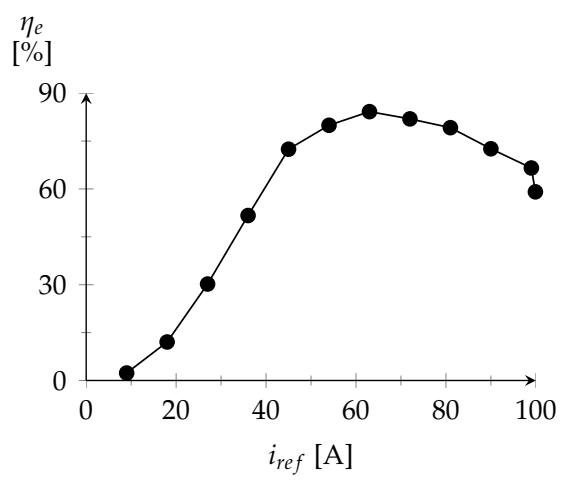

(b)

Figure 12. Energy conversion performance for different values of $i_{\text {ref }}$ : (a) mean value of generated electric power; and (b) electric conversion efficiency.

Table 3 presents the energetic conversion performance parameters of the system operating with the proposed MPPT control strategy and with the control at constant $i_{r e f}$. The latte is classified with the values obtained for the highest value of average generated electric power.

The excitation force profile adopted for each simulation can be observed in Figure 13a. The $i_{\text {ref }}$ profile provided by the MPPT controller is exposed in Figure 13b. The oscillating body absolute position and velocity are presented, respectively, in Figure 14a,b for the operation with constant $i_{\text {ref }}$ and variable $i_{r e f}$. The corresponding phase current intensity and electromechanical force are displayed, respectively, in Figures 15 and 16. The DC bus voltage level is represented in Figure 17.

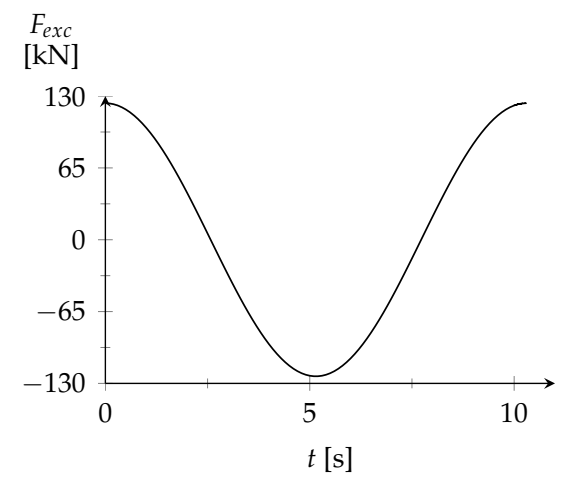

(a)

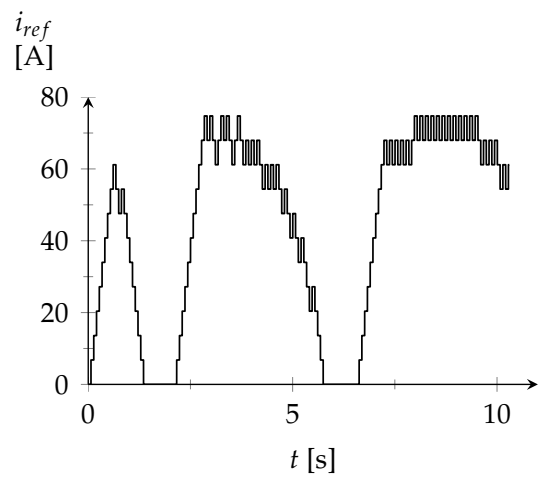

(b)

Figure 13. Simulated profile for: (a) excitation force; and (b) $i_{r e f}$ obtained with MPPT. 
Table 3. Energetic conversion performance of the TLSRG with MPPT control and constant $i_{r e f}$ control.

\begin{tabular}{ccccccc}
\hline \multicolumn{3}{c}{ Variable $i_{\text {ref }}$} & \multicolumn{4}{c}{ Constant $i_{\text {ref }}$} \\
\hline $\begin{array}{c}\overline{\boldsymbol{P}}_{\text {mech }} \\
{[\mathbf{k W}]}\end{array}$ & $\overline{\boldsymbol{P}}_{\text {gen }}$ & $\boldsymbol{\eta}_{\boldsymbol{e}}$ & $\boldsymbol{i}_{\text {ref }}$ & $\overline{\boldsymbol{P}}_{\text {mech }}$ & $\overline{\boldsymbol{P}}_{\boldsymbol{g e n}}$ & $\boldsymbol{\eta}_{\boldsymbol{e}}$ \\
{$[\mathbf{k W}]$} & {$[\%]$} & {$[\mathbf{A}]$} & {$[\mathbf{k W}]$} & {$[\mathbf{k W}]$} & {$[\%]$} \\
\hline 59.1 & 53.1 & 89.9 & 54.0 & 57.2 & 45.7 & 79.9 \\
\hline
\end{tabular}

- Variable $i_{\text {ref }} \_$Constant $i_{\text {ref }}$

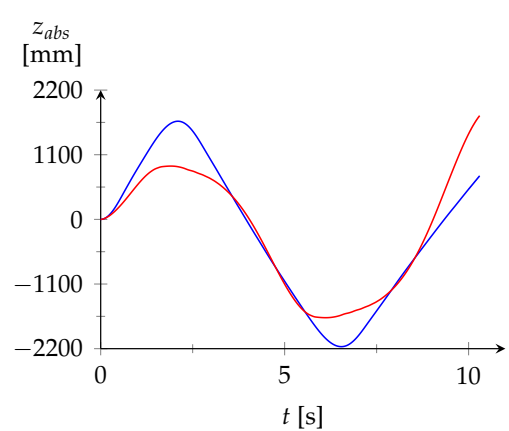

(a)

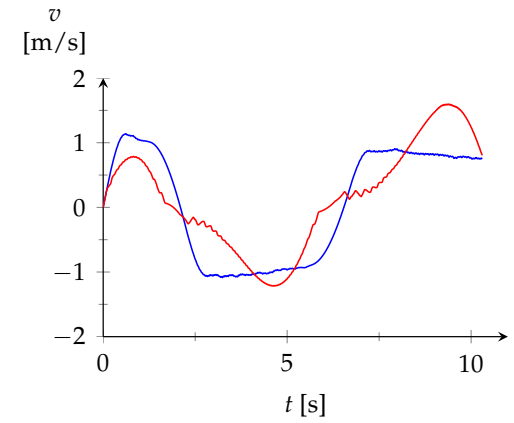

(b)

Figure 14. Oscillating body profile for: (a) absolute position; and (b) linear velocity.

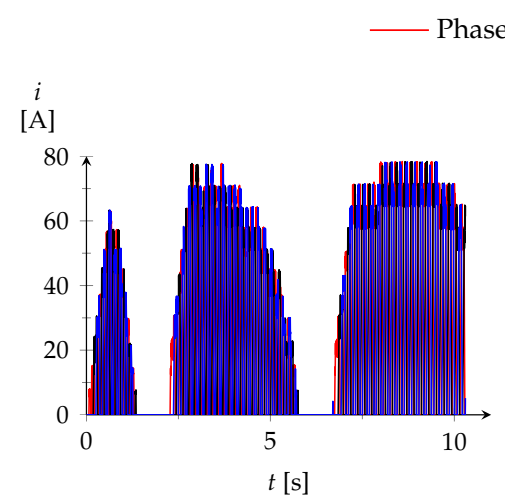

(a)

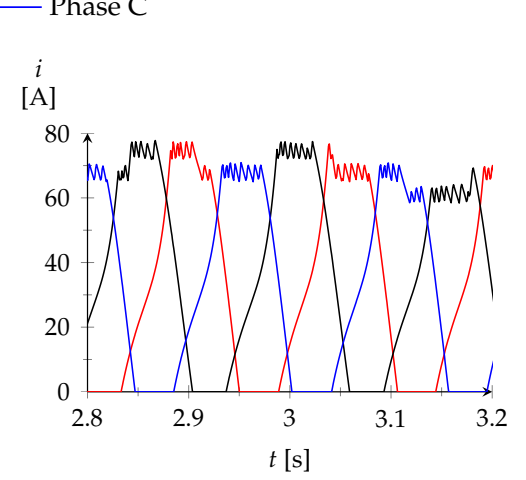

(b)

Figure 15. Electric current profile for each electric phase: (a) normal view; and (b) zoomed view.

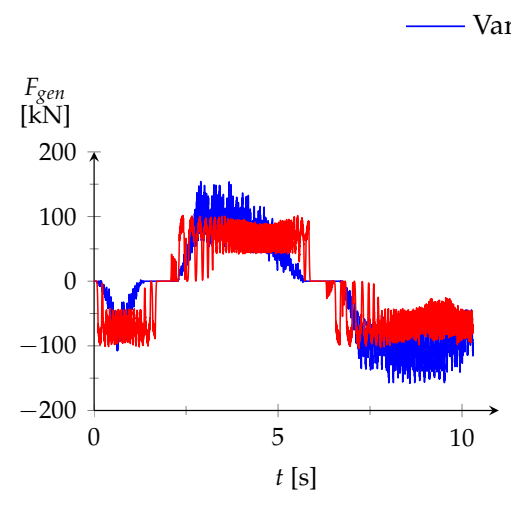

(a)

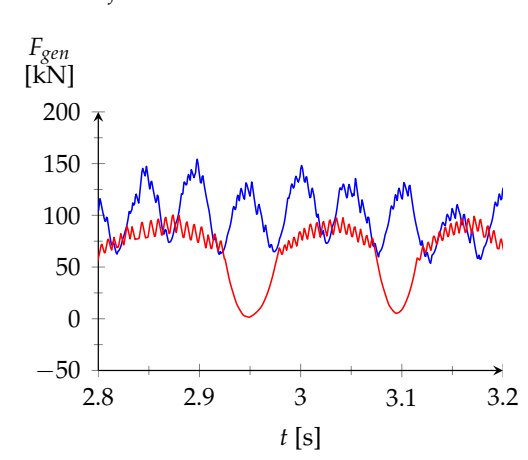

(b)

Figure 16. Generator electromagnetic force profile: (a) normal view; and (b) zoomed view. 


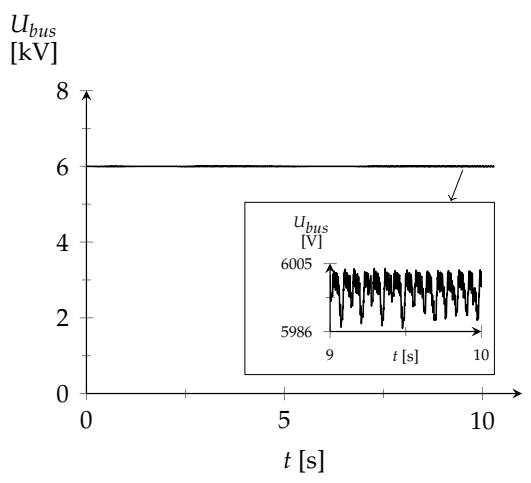

Figure 17. DC bus voltage profile.

From the simulations with constant current control, a better performance was verified for inferior values of $i_{r e f}$, in respect to the maximum value specified. The best scenario was characterized with an average electric power of $45.7 \mathrm{~kW}$ for a reference current of $54 \mathrm{~A}$. However, better performance was achieved with the proposed MPPT control strategy where $53.1 \mathrm{~kW}$ of average generated electric power was obtained with greater electric conversion efficiency.

While operating with a constant lower damping force, the system does not become over-damped when the wave loads are reduced and, as a consequence, the average mechanical power extracted may be increased. Although reduced, the generator force may still be excessive for some stages of the conversion cycle and not sufficient to extract the maximum available power when the wave excitation load reaches its peak value. Regulating the value of $i_{r e f}$, these drawbacks are minimized since the damping of the TLSRG follows the excitation force induced by the wave with the goal to attain the maximum power generation conditions. However, for a variable $i_{r e f}$, the electric phase current is also more irregular which increases the fluctuations of the TLSRG electromechanical force, when compared with a constant reference current control. Nevertheless, the fluctuations are not evident in the oscillating body displacement because of the attenuation provided by inertia of the moving system. The PI controller, applied to the isolated DC/DC converter, was also effective in maintaining the voltage level of the DC bus close to the respective nominal value. During the simulation period, a maximum voltage error of $0.22 \%$ was verified.

\section{Conclusions}

This work proposed a new MPPT control strategy for a Tubular Linear Switched Reluctance Generator with application in a direct drive point absorber device. The control strategy was designed to attain maximum power extraction by adapting the TLSRG damping force to the variable excitation load induced by the ocean waves. The system performance was simulated for a loading profile of a regular wave. For the same excitation conditions, the system has been evaluated for a constant damping operation, where different force values were considered. With the proposed control strategy, the system was able to generate more electrical energy, in comparison with the results obtained for a constant damping operation. Thus, it was concluded that the proposed control strategy is suitable for a TLSRG operating under the loading conditions imposed by a regular wave.

As future work, the performance of the conversion system with the proposed control technique can be extended for operation under irregular ocean waves. Other existing control strategies may also be evaluated in this type of generator to serve as a comparative study with the proposed approach. A small scale prototype is under construction to validate the obtained results.

Author Contributions: Conceptualization, R.M. and M.d.R.C.; Methodology, R.M. and M.d.R.C.; Software, R.M. and S.M.; Investigation, R.M., M.d.R.C. and S.M.; Supervision, M.d.R.C.; Writing-Original Draft Preparation, R.M.; Writing-Review \& Editing, R.M., M.d.R.C. and S.M. 
Acknowledgments: Rui Mendes gives his special thanks to the Fundação para a Ciência e a Tecnologia, Portugal (FCT) for the Ph.D. Grant (SFRH/BD/91626/2012) and to the Instituto de Telecomunicações for the Research Grant BPD/No 24 13/04/2018 UID/EEA/50008/2018.

Conflicts of Interest: The authors declare no conflict of interest.

\section{References}

1. Pastor, J.; Liu, Y. Frequency and time domain modeling and power output for a heaving point absorber wave energy converter. Int. J. Energy Environ. Eng. 2014, 5, 101. [CrossRef]

2. Feng, N.; Yu, H.; Hu, M.; Liu, C.; Huang, L.; Shi, Z. A Study on a Linear Magnetic-Geared Interior Permanent Magnet Generator for Direct-Drive Wave Energy Conversion. Energies 2016, 9, 487. [CrossRef]

3. Huang, L.; Hu, M.; Chen, Z.; Yu, H.; Liu, C. Research on a Direct-Drive Wave Energy Converter Using an Outer-PM Linear Tubular Generator. IEEE Trans. Magn. 2017, 53, 1-4. [CrossRef]

4. Xia, T.; Yu, H.; Chen, Z.; Huang, L.; Liu, X.; Hu, M. Design and Analysis of a Field-Modulated Tubular Linear Permanent Magnet Generator for Direct-Drive Wave Energy Conversion. IEEE Trans. Magn. 2017, 53, 1-4. [CrossRef]

5. Zhang, J.; Yu, H.; Shi, Z. Design and Experiment Analysis of a Direct-Drive Wave Energy Converter with a Linear Generator. Energies 2018, 11, 735. [CrossRef]

6. Gao, Y.; Shao, S.; Zou, H.; Tang, M.; Xu, H.; Tian, C. A fully floating system for a wave energy converter with direct-driven linear generator. Energy 2016, 95, 99-109. [CrossRef]

7. Pan, J.F.; Yu, Z.; Cheung, N.; Cao, G.Z. On the Voltage Ripple Reduction Control of the Linear Switched Reluctance Generator for Wave Energy Utilization. IEEE Trans. Power Electron. 2014, 29, 5298-5307. [CrossRef]

8. Moreau, L.; Zaïm, M.E.; Machmoum, M. Electromagnetic design optimization of a low speed Slotted Switched Reluctance Machine using genetic algorithm. In Proceedings of the 2012 XXth International Conference on Electrical Machines (ICEM), Marseille, France, 2-5 September 2012; pp. 233-237. [CrossRef]

9. Aderinto, T.; Li, H. Ocean Wave Energy Converters: Status and Challenges. Energies 2018, 11, 1250. [CrossRef]

10. Babarit, A.; Clément, A. Optimal latching control of a wave energy device in regular and irregular waves. Appl. Ocean Res. 2006, 28, 77-91. [CrossRef]

11. Tedeschi, E.; Molinas, M. Tunable Control Strategy for Wave Energy Converters With Limited Power Takeoff Rating. IEEE Trans. Ind. Electron. 2012, 59, 3838-3846. [CrossRef]

12. Babarit, A.; Duclos, G.; Clément, A. Comparison of latching control strategies for a heaving wave energy device in random sea. Appl. Ocean Res. 2004, 26, 227-238. [CrossRef]

13. Jama, M.; Wahyudie, A.; Assi, A.; Noura, H. An Intelligent Fuzzy Logic Controller for Maximum Power Capture of Point Absorbers. Energies 2014, 7, 4033-4053. [CrossRef]

14. Mendonca, H.; Martinez, S. A resistance emulation approach to optimize the wave energy harvesting for a direct drive point absorber. IEEE Trans. Sustain. Energy 2016, 7, 3-11. [CrossRef]

15. Kurupath, V.; Ekström, R.; Leijon, M. Optimal Constant DC Link Voltage Operation of a Wave Energy Converter. Energies 2013, 6, 1993-2006. [CrossRef]

16. Villa-Jaen, A.; Montoya, D.E.; Garcia-Santana, A. Control Strategies for Point Absorbers Considering Linear Generator Copper Losses and Maximum Excursion Constraints. IEEE Trans. Sustain. Energy 2018, 9, 433-442. [CrossRef]

17. Anderlini, E.; Forehand, D.I.M.; Stansell, P.; Xiao, Q.; Abusara, M. Control of a Point Absorber Using Reinforcement Learning. IEEE Trans. Sustain. Energy 2016, 7, 1681-1690. [CrossRef]

18. Son, D.; Yeung, R.W. Real-time implementation and validation of optimal damping control for a permanent-magnet linear generator in wave energy extraction. Appl. Energy 2017, 208, 571-579. [CrossRef]

19. Oh, Y.J.; Park, J.S.; Hyon, B.J.; Lee, J. Novel Control Strategy of Wave Energy Converter Using Linear Permanent Magnet Synchronous Generator. IEEE Trans. Appl. Supercond. 2018, 28. [CrossRef]

20. Jama, M.; Wahyudie, A.; Noura, H. Robust predictive control for heaving wave energy converters. Control Eng. Pract. 2018, 77, 138-149. [CrossRef]

21. Lettenmaier, T.; von Jouanne, A.; Brekken, T. A new maximum power point tracking algorithm for ocean wave energy converters. Int. J. Mar. Energy 2017, 17, 40-55. [CrossRef] 
22. Park, J.S.; Gu, B.G.; Kim, J.R.; Cho, I.H.; Jeong, I.; Lee, J. Active Phase Control for Maximum Power Point Tracking of Linear Wave Generator. IEEE Trans. Power Electron. 2017, 32, 7651-7662. [CrossRef]

23. Mendes, R.; Calado, M.; Mariano, S. Analysis of the influence of different topologies on a TLSRG generation performance for WEC. Eng. Lett. 2014, 22, 202-208.

24. Filho, P.S.N.; de Oliveira, L.R.; dos Santos Barros, T.A.; Villalva, M.G.; Filho, E.R. Modeling and digital control of a high-power full-bridge isolated DC-DC buck converter designed for a two-stage grid-tie PV inverter. In Proceedings of the 2014 IEEE Energy Conversion Congress and Exposition (ECCE), Pittsburgh, PA, USA, 14-18 September 2014; pp. 1874-1879. [CrossRef]

25. Babarit, A.; Hals, J.; Muliawan, M.J.; Kurniawan, A.; Moan, T.; Krokstad, J. Numerical benchmarking study of a selection of wave energy converters. Renew. Energy 2012, 41, 44-63. [CrossRef]

26. Det Norske Veritas AS. Recommended Practice DNV-RP-H103: Modelling and Analysis of Marine Operations; Technical Report; Det Norske Veritas AS: Oslo, Norway, 2014.

27. MacMinn, S.R.; Sember, J.W. Control of a switched-reluctance aircraft engine starter-generator over a very wide speed range. In Proceedings of the 24th Intersociety Energy Conversion Engineering Conference (IECEC-89), Washington, DC, USA, 6-11 August 1989; Volume 1, pp. 631-638. [CrossRef]

28. Mobarrez, M.; Fazlali, M.; Bahmani, M.A.; Thiringer, T. Performance and loss evaluation of a hard and soft switched 2.4 MW, $4 \mathrm{kV}$ to $6 \mathrm{kV}$ isolated DC-DC converter for a wind energy application. In Proceedings of the IECON 2012 - 38th Annual Conference on IEEE Industrial Electronics Society, Montreal, QC, Canada, 25-28 October 2012; pp. 5086-5091. [CrossRef]

29. Shao, B.; Emadi, A. A digital control for switched reluctance generators. In Proceedings of the 2011 IEEE International Conference on Mechatronics (ICM), Istanbul, Turkey, 13-15 April 2011; pp. 182-187. [CrossRef]

30. Cardenas, R.; Pena, R.; Perez, M.; Clare, J.; Asher, G.; Wheeler, P. Control of a switched reluctance generator for variable-speed wind energy applications. IEEE Trans. Energy Convers. 2005, 20, 781-791. [CrossRef]

31. Choi, D.W.; Byun, S.I.; Cho, Y.H. A Study on the Maximum Power Control Method of Switched Reluctance Generator for Wind Turbine. IEEE Trans. Magn. 2014, 50. [CrossRef]

32. Rahmanian, E.; Akbari, H.; Sheisi, G.H. Maximum Power Point Tracking in Grid Connected Wind Plant by Using Intelligent Controller and Switched Reluctance Generator. IEEE Trans. Sustain. Energy 2017, 8, 1313-1320. [CrossRef]

33. Amon, E.A.; Brekken, T.K.A.; Schacher, A.A. Maximum Power Point Tracking for Ocean Wave Energy Conversion. IEEE Trans. Ind. Appl. 2012, 48, 1079-1086. [CrossRef]

34. Xiong, L.; Xu, B.; Gao, H.; Xu, L. A novel algorithm of switched reluctance generator for maximum power point tracking in wind turbine application. In Proceedings of the 2009 International Conference on Sustainable Power Generation and Supply, Nanjing, China, 6-7 April 2009; pp. 1-5. [CrossRef]

35. Park, K.; Chen, Z. Self-tuning fuzzy logic control of a switched reluctance generator for wind energy applications. In Proceedings of the 2012 3rd IEEE International Symposium on Power Electronics for Distributed Generation Systems (PEDG), Aalborg, Denmark, 25-28 June 2012; pp. 357-363. [CrossRef]

36. El-Nagar, A.M. Embedded intelligent adaptive PI controller for an electromechanical system. ISA Trans. 2016, 64, 314-327. [CrossRef] [PubMed]

37. Babarit, A.; Delhommeau, G. Theoretical and numerical aspects of the open source BEM solver NEMOH. In Proceedings of the 11th European Wave and Tidal Energy Conference (EWTEC2015), Nantes, France, 6-11 September 2015.

38. Mendes, R.; Calado, M.; Mariano, S. Particle swarm and Box's complex optimization methods to design linear tubular switched reluctance generators for wave energy conversion. Swarm Evol. Comput. 2016, 28, 29-41. [CrossRef]

(C) 2018 by the authors. Licensee MDPI, Basel, Switzerland. This article is an open access article distributed under the terms and conditions of the Creative Commons Attribution (CC BY) license (http:/ / creativecommons.org/licenses/by/4.0/). 